\title{
Universality of Social Health - Lessons from the Mahatma
}

\author{
Indranil Chakravorty PhD FRCP
}

Consultant Physician, St Georges University Hospitals NHS Trust \& Deputy Postgraduate

Dean, Health Education England (London North Central \& East)

\section{Indranil.chakravorty@stgeorges.nhs.uk}

\section{Cite as:}

Chakravorty I. Editorial: Universality of Social Health - Lessons from the Mahatma. Sushruta 2019 (Nov) 12(1):5 ePub 21.11.2020 DOI: 10.38192/12.1.1

\section{Keywords}

universal healthcare, NHS, Mahatma Gandhi, Commonwealth, glass ceilings, leadership

As you read the articles that I have had the pleasure to curate for this special edition of SUSHRUTA, published along with the \#BAPIOAC19 conference in London this wet and frosty November, you will see glimmers of hope and aspirations of a broad-church of people that make up the health service. NHS professionals come from all over the world, bringing their cultures from distant shores that were once touched by the British Empire (now the Commonwealth) You will also witness the ambitious plans for future proofing what is arguably the best universal health system in the world. It is a time for 20/20 vision; we recognise not only the challenges that face the UK population and the NHS but we also envisage how the strengths of the diverse multi-skilled workforce come together in making the UK NHS star shine even brighter.

This is a time when we will hear of many promises from the various contenders for the UK parliamentary elections. As health professionals, we are sworn to absolute dedication to our patients, their care and safety. Most of us would shun, both in public and private life, involvement in any form of political discourse. As scientists we are trained to speak only when the evidence is compelling and that too providing a balanced objective view, yet medicine is an art and healthcare professionals are humanists. It is true that health professionals have not ignored the power of political discourse in changing the fate of their patients and their profession. In the 1500s medical practice in England was poorly regulated. Many 'physicians' were working with no formal training or knowledge. The leading physicians of the early 16th century wanted the power to grant licenses to those with actual qualifications and to restrict unqualified practitioners and those engaging in malpractice. A group of physicians led by Thomas Linacre petitioned King Henry VIII to establish a college of physicians in 1518 . Even to this day, one of the key responsibilities of the Royal Colleges and professional organisations remains to petition the government, present compelling evidence and seek changes that will eventually improve the health of the nation. 
Mohan Das Karamchand Gandhi, also known as Mahatma Gandhi may indeed be a controversial figure in his homeland, but is a global leader and is revered across the world for the principles with which he led his life and brought about enormous systemic changes for the improvement of the lives of ordinary people. In his $150^{\text {th }}$ year of birth, we have an opportunity to reflect on how his belief in humanity, his principles of universal justice, selfsacrifice and leadership from the frontline are as relevant today, as they were when he undertook his 240 mile walk in 1939 across the salt flats of Gujarat in protest against the unfair and draconian salt tax imposed by the British government. His leadership qualities such as selfless service to humanity, self-sacrificial love, spirituality, integrity and humble living, were emulated by many transformational world leaders who drew inspiration from his life. He stood out for the essential principle that all men are equal and artificial distinctions based on race and colour were both unreasonable and immoral. He practiced what he preached and that can be such a powerful motivator for all. Unfortunately, in spite of the principles of universality that is in the founding principles of the NHS, the reality can be very different. There are significant differences in the health outcomes of segments of the population within boroughs, post codes and health sectors. The trajectory of the careers of healthcare professionals is no different; reflected in the differential attainment of students, the career progression of workers and 'glass ceilings' that present often insurmountable hurdles for ambitious individuals based on their gender, disability or racial characteristics. We will hear of initiatives that are being led by individuals and institutions to change this paradigm and close the achievement gap.

In this November national conference, we will be focussing on the multi-professional workforce, listening to the experience of extended roles from pharmacists, physician associates, advanced nursing, debate the funding models for the NHS, examine closely the educational and training pathways and learn from innovators from across the globe. Through our networks we will be reaching out to global health partnerships as we understand that improvement in UK population health cannot be divorced from the impact of health care related migration.

Organisations such as BAPIO, provide a voice to many who have often not been heard as they have toiled tirelessly in keeping this massive social movement, the very best 'Marigold Hotel' afloat and thriving. Such organisations hold a mirror up to organisations, provide a friendly challenge where there is a reluctance to open one's eyes and most importantly offer solutions in partnership, to move towards universality of access to the best healthcare for all patients and opportunities with a level playing field for each and every professional to reach their potential. This is the only way that a society can move forward and reach the World Health Organisations vision of Health for All. 